\title{
LIVED EXPERIENCES OF WOMEN ENTREPRENEURS IN MASVINGO CITY: SUCCESSES, FAILURES AND SURVIVAL STRATEGIES
}

\author{
Dr Takupiwa Nyanga' ORCID: 0000-0001-5243-6680
}

\begin{abstract}
:
There has been a significant increase in the number of women entrepreneurs in various sectors of the economy throughout the world. Some women entrepreneurs registered some success stories, while others dismally failed and ended up poorer than they were before they started their businesses. The main purpose of this study was to establish the successes, failures and survival strategies of women entrepreneurs in Masvingo city, Zimbabwe. A qualitative research methodology was employed to carry out the study. Face-to-face semi-structured interviews were conducted on 40 (forty) participants who were selected by using the snowball sampling technique. Thematic data analysis approach was utilized to analyse the collected data. It was found that despite some registered failures and challenges like failing to retain staff, failing to raise adequate capital, and failing to access advanced technology, a significant number of women entrepreneurs were generally successful in launching, maintaining and growing their businesses. The strategies which women entrepreneurs employed to survive, included among others, buying raw materials or goods for resale in bulk to enjoy the economies of scale; pegging prices and selling their products in United States Dollars (USD); pegging prices in USD and selling products at the prevailing Zimbabwean Dollar exchange rate; or hiring competent staff to ensure that workers were appropriately motivated. It was recommended that women entrepreneurs should continuously scan the macro- and micro-environments to identify new opportunities as well as emerging business threats.
\end{abstract}

Keywords: Entrepreneurship, women entrepreneur, job satisfaction, SMEs, survival strategies

\section{Introduction}

The number of female entrepreneurs and self-employed women have grown phenomenally over the past four decades, putting them at an approximate thirty-six percent of global entrepreneurship activities (Erickson 2017). Women enter into various forms of businesses throughout the world at an overwhelming rate. Although the number of women entrepreneurs is still far below the number of men entrepreneurs, the significance of new women entrants into various types of businesses cannot be ignored. Nyanga and Chindanya (2021) applauded women entrepreneurs in Zimbabwe and beyond for maneuvering and entering into various types of industries, however, they lamented the slow and stunted growth of the majority of their businesses. In the same vein Nyanga, Sibanda and Kruger (2018) also observed that women in both peaceful and armed conflict societies venture into various types of businesses, but most of their businesses continue to be home-based business ventures which do not grow into big business ventures. The increase in the number of women entrepreneurs in Zimbabwe and beyond has

1Julius Nyerere School of Social Sciences, Department of Human

Resource Management, Great Zimbabwe University

Email: takupiwa@gmail.com

Journal of Entrepreneurial Innovations Vol. 2 (1) 
triggered the interests of many researchers to perform researches on female entrepreneurship (Black, Burton, Wood and Zimbelman 2010, OECD 2015, Scott and Venkatraman 2000, Yetisen, Volpatti, Coskun, Cho, Kamrani, Butt, Khademhosseini and Yun 2015, Zhang and Cueto 2015, Nyanga 2013). Most studies on entrepreneurship sought to establish the contribution of SMEs (Barbara, Catherine, and Joanne, 2011; Brush, Greene, Balachandra and Davis, 2018, Carter, Brush, Greene, Gatewood and Hart 2003; Eddleston, Ladge, Mitteness and Balachandra 2016; Gayathridevi, 2014; Malmstrom, Johansson and Wincent 2017; Tinkler, Bunker, Ku, and Davies 2015 ) to economic growth in general, the reduction of unemployment rate and to poverty eradication. Most entrepreneurship studies, however, grouped men and women entrepreneurs together, which has made it difficult to measure the contribution of each category. The need to establish the contribution of each category, the successes, failures and survival strategies of each category, propelled the need to carry out this study.

A woman entrepreneur is a female who typically controls a commercial venture by directing and organizing all the factors of production such as the human capital, finance, material resources and information and communication technology, for purposes of maximizing the available business opportunities and finding appropriate ways of managing threats (Erickson 2017). Woman entrepreneurs perform roles of managers and oversee the launch, survival and growth of their businesses or enterprises. A female entrepreneur identifies, utilizes and maximizes a business opportunity. The entrepreneur then amasses and appropriately deploys the required materials, tools and resources to exploit the identified opportunities. The female entrepreneur maximizes the identified entrepreneurial opportunities by engaging in business activities such as putting in place the required materials, hiring employees, acquiring financial and material resources and providing good leadership and management (Nyanga and Chindanya 2021). Women entrepreneurs are expected to plan, organize, design, launch and manage their new businesses for purposes of producing products and services for sale or for hire to their clients. Women entrepreneurship is the capacity, ability, aptitude and willingness of a woman to develop, organize, and manage an enterprise along with any of the risks associated with it, to make a profit and to increase the value of the shares.

A study by Black et al. (2010) established that the credit crisis made it extremely difficult for entrepreneurs to access funding from various institutions. It is therefore essential for entrepreneurs, including female entrepreneurs, to know what is required when dealing with funding issues. Entrepreneurs need to come up with essential funding decisions to access funding, since it is the cornerstone for the success of any enterprise. An enterprise without or with limited funding is bound to fail. Furthermore, a study by Nyanga et al. (2013) established that most SMEs fail to achieve their objectives, because of a host of factors such as poor funding, poor leadership style, failure to properly position themselves. Gayathridevi (2014) also carried out a study in Bangalore Urban District in India to establish the barriers of women entrepreneurs, and he found that women entrepreneurs face several challenges that impede them from realizing their set goals and objectives. Several studies (Barbara et al 2011, Brush et al 2018, Carter et al. 2003, Eddleston et al. 2016, Gayathridevi, 2014, Malmstrom et al. 2017, Tinkler, et al. 2015) have shown that women entrepreneurs play an essential role in the economic development and transformation of any country. Nyanga et al. (2013) have also indicated that many women have been motivated to start their businesses, mainly by the deliberate efforts made by governments and civil societies to support them in starting and maintaining their businesses. The transformation of culture and gender activism made women acceptable as key players and equal partners in businesses. However, a reasonable number of businesses were due to fold, because of a lack of funding, bad business decisions, economic crisis, or due to a lack of market demand. Women entrepreneurs in the city of Masvingo in Zimbabwe and beyond have not been spared the challenges that other entrepreneurs are faced with across the globe.

Like all other forms of entrepreneurial ventures, female entrepreneurship operates within an entrepreneurship ecosystem, which comprises all government and non-governmental programs and activities that promote start-ups and support entrepreneurial initiatives. For instance, the government of Zimbabwe introduced Small Enterprise Development Corporations (SEDCO) that have the mandate of overseeing and providing support and advice to all small to medium enterprises in the country. More friendly laws, regulations and policies that create a conducive environment for start-ups were created. The Zimbabwean economy is mainly anchored by SMEs and its GDP heavily depends on the performance of SMEs in various industries. In a bid to grow the economy, the government ofZimbabwe increased the number of entrepreneurial activities by taking a deliberate move to introduce entrepreneurship studies in the secondary school as well as in the tertiary and higher education curriculum (Nyanga and Chindanya 2021). Entrepreneurship in Zimbabwe is studied in teachers colleges, polytechnic colleges, vocational training centers and universities, to increase the incubation of business ventures. A deliberate move to enroll more women in entrepreneurship-related programs is done at all levels of education. The government of Zimbabwe, through the Ministry of Higher and Tertiary Education, Science and Technology Development, also introduced innovation 
hubs at universities to champion the incubation of business ideas and thoughts. The deliberate move to introduce business incubation hubs throughout the country by the Ministry of Higher and Tertiary Education, Science and Technology Development, created an opportunity for women to venture into entrepreneurial activities, such as buying and selling, as well as manufacturing of detergents. The female entrepreneurs, however, experienced a mixture of fortunes and misfortunes. Some met some challenges and failed to survive, while others have some success stories and contributed significantly to poverty eradication and economic growth. The purpose of this research was to establish the successes, failures and survival strategies of female entrepreneurs.

\section{Rationale}

The study is essential because it provides useful insights on policy formulation at company, industry and national levels. For women entrepreneurs to be successful and grow their organizations, they need to be supported by policy which is deliberately formulated to address their needs and requirements. The study clearly outlines the problems, challenges and failures encountered by women entrepreneurs and it proffers suggestions to solve them. This would cause women to manage SMEs to survive and grow, even if they were operating in economically distressed environments. The successes and achievements of women entrepreneurs were also revealed, and these served as an eye-opener for women entrepreneurs to know what they were doing right, so that they would continue or even further improve on what they were doing. The government also needs to fully support women who manage SMEs, hence, this study provides it with adequate information on what needs to be done and at what stage SMEs managed by women should be successful.

\section{Objectives}

The objectives of this study were as follows:

- To determine the successes and achievements of women entrepreneurs in Masvingo city.

- To establish business practices and other factors which contribute to the failure of women entrepreneurs in Masvingo city.

- To evaluate survival strategies employed by women entrepreneurs in Masvingo city.

\section{Methodology}

The city of Masvingo is home to several women entrepreneurs operating in various sectors of the economy. Synonymous with what is happening in most parts of the country, the majority businesses established, managed and owned by women in various industries in Masvingo city, closed due to unfavourable macro-environmental factors such as the distressed economy. The closure of several industries in the city opened a door for many entrepreneurs to start their businesses in various areas, such as manufacturing of home detergents, building material, and others. Women entrepreneurs were also not left out in starting various types of businesses in the city. Most women, however, were mainly involved in the business of buying and selling, and also in manufacturing goods on a small scale, such as making peanut butter and maputi. The cross-border trading business, however, dominated all the other types of businesses.

To get an in-depth analysis and finer details of issues under investigation, a qualitative research approach was utilized. The qualitative approach was adopted, because the researcher intended to cater for various groups of the study population, such as the literate and the illiterate. Furthermore, the qualitative approach was the best approach for this study, because issues under discussion needed to be thoroughly scrutinized. The study population comprised women entrepreneurs operating various types of businesses in Masvingo city. According to Nyanga and Chindanya (2021) the types of businesses managed by women entrepreneurs in Masvingo include small scale manufacturing, buying and selling, cross-border trading, airtime vending and many others which require small capital. The population of the study was approximately 500 . The exact population could not be established, since some of the entrepreneurs operated informally. The sample of the study comprised 40 (forty) participants who were selected using the snowball sampling technique. The researcher started by identifying one well-known and successful crossborder woman entrepreneur whose business is at the Chitima market in Masvingo town. The woman entrepreneur then referred the researcher to other cross- border women entrepreneurs. The study purposely targeted a sample of women entrepreneurs who were either high-growth oriented, or who engaged in entrepreneurship out of necessity, and therefore the sample involves entrepreneurs who are engaged in various types of businesses. The majority of the participants were cross-border traders who import goods for resale from various countries such as South Africa, Tanzania, Zambia, China, Japan, and other economically emerging or developing countries. To solicit data from the sample, a self-designed face-to-face semi-structured interview guide was employed. Face-to-face interviews 
were adopted, because they were found to be the most versatile form of collecting data from a population which comprises both literates and illiterates. Interviews also helped the researcher to get detailed perceptions, opinions and attitudes from women entrepreneurs in Masvingo. In order to gain deeper insight, to effectively probe further, and also to observe participants' facial expressions, the interviews were conducted in person but in full compliance with the COVID-19 regulations. The data collection instrument that was employed, offered an advantage over selfcompletion methods such as a questionnaire, because interviewees are more likely to give their full attention to the interview session, which enables the interviewer to probe further. To ensure that the instruments were accurate in measuring what they should measure, the researcher carried out a pilot study in Zvishavane town, which is 90 kilometers from Masvingo city - the study area. Data was analyzed using thematic data analysis. Themes and subthemes were drawn from the respondents' responses. Themes and sub-themes were drawn from the interview audio recordings and notes that were written by the interviewer.

\section{Findings}

The participants of the study comprised 40 women entrepreneurs whose educational qualifications ranged from Grade 5 to doctoral degree level. The qualifications of the participants imply that any person, irrespective of their level of education, can be a business entrepreneur. However, it was noted that those participants with lower qualifications, have limitations in a number of areas that require strategic thinking and analysis, and also to hedge their organizations from the adverse effects of economic and socio-political upheavals. The age range of the participants was between 17 and 67 years. It shows that almost all age groups within the working fraternity are represented. The 17-year-old category, however, shows that there is an element of child labour, since the law outlines 18 years as the legal age of majority. The findings are consistent with Gukurume and Nyanga (2013) who observed that child labour was rampant in the Mucheke suburb in Masvingo, where some children abandon school and engage in the business of buying and selling, while others engage in business ventures after school to raise their school fees. In terms of marital status, participants were distributed as follows: married $=6$, single $=9$, widowed $=15$ and divorced $=10$. The distribution of participants in terms of marital status, shows that the majority of the participants were not married. The widowed and divorced categories dominated all the other categories. This is because most women decide to engage in income-generating projects after losing their spouses through death or divorce, where the spouse provided the major source of income. Most housewives who lose their husbands or are in broken marriages, are left with no option but to engage in income-generating activities to take care of themselves and their children. Most women entrepreneurs who participated in the study had been in business for a period that ranged from 1 to 28 years. The majority of women entrepreneurs were in the business of buying and selling (cross-border traders), small-scale manufacturing and farming. Only 2 (two) participants were into mining.

The study also indicated that most successful women entrepreneurs in Zimbabwe began their businesses as a second or third profession. They maximized their previous careers to enter into the business world, hence, the majority started their businesses in their early or late 40s. Some women entrepreneurs started their professional lives as teachers, nurses, doctors and engineers. The teaching fraternity, however, dominated the other sectors. According to the Global Entrepreneurship Monitor report (2015), "women are nearly one-third more likely to start businesses out of necessity than men."

In terms of the successes achieved by women entrepreneurs, the study revealed that most female entrepreneurs managed to hedge their organizations from the macro- environmental upheavals that have been bedeviling the country for the past two decades, by regularly scanning the environment and making sure that their businesses were not exposed to risks. Most women entrepreneurs managed to grow their businesses from small to medium and medium to large corporations, because of their ability to appropriately position their organizations and maximizing the available opportunities. For instance, a shortage of a commodity such as cooking oil in Masvingo, triggers importation of the product in huge quantities, which in turn make entrepreneurs benefit from the economies of scale. One of the participants said, "I managed to grow my business from a small-scale shop, which was operating under the tree, to a medium-scale enterprise, operating from a well-furnished building infrastructure. The growth of my business was propelled and triggered by my ability to utilize funding opportunities that were provided by the government through the Ministries of Youth and Small to Medium Enterprises. I managed to get adequate capital to buy large quantities of goods to restock my business, which consequently led me hedge my business from the rising inflationary environment." Participant 12 said, "I closely follow the development in the political, economic, social and technological environments, hence, I quickly pick all key business opportunities and grab them and also quickly identify the major business threats. " Most women entrepreneurs in Zimbabwe are credited for managing to grow their organizations and protecting them from the economic distress that has been affecting the country for a 
very long time. In most industries SMEs have become the engines for the supply of goods and services, because most big players closed their businesses during the 2008 economic meltdown. Women entrepreneurs are therefore credited for keeping industries that provide essential goods and services afloat. Women entrepreneurs presented themselves as serious business leaders, generators and innovators of new and very useful ideas that can help businesses to grow and also provide the much-needed products in the right quantities and quality. Entrepreneurs successfully perceived new business opportunities and exhibited a positive attitude toward their perception. Most women entrepreneurs have grown to become risk-takers that could exploit the available opportunities with ease.

The findings also showed that one of the successes scored by women entrepreneurs was the full utilization of modern-day information communication technology and systems to market their products and services that acquire raw materials to distribute their products. Women entrepreneurs utilize social media such as WhatsApp to market and communicate with their clients, suppliers and transporters. Social media such as Twitter, Facebook, WhatsApp and others, are heavily utilized in disseminating information to key business stakeholders. The use of social media as a mode of communication significantly reduces transport and communication costs, stationary costs, and it saves time for the entrepreneur (Nyanga and Chindanya 2021). For instance, cross-border traders can order their goods through WhatsApp from India, South Africa, Tanzania, China or anywhere in the world. Participant 8 said, "I order my goods for resale from South Africa and Tanzania using WhatsApp, hence, I significantly reduce my transport and logistics costs." Participant 19 remarked, "I rely on e-business when I order my raw materials to manufacture detergents. I buy most of the chemicals from South Africa and China, but I rarely visit those countries, because I use an email to make my order and also use e-banking systems to make payments. I then contact the transporters using social media and also email. The strategy significantly reduced my production costs." The findings are consistent with Cuaton (2019) who argues, "Supply of raw materials is not only hampered by the depleting natural resources but also by the availability of drying facilities." It implies that successful women entrepreneurs need to find ways and strategies of getting their raw materials on time, in the correct quantities, and at a low cost. The majority of women entrepreneurs who engage in the business of buying and selling goods, imported from better developed economies, and they successfully managed to acquire their goods at low costs and on time, because of their strategy of taking advantage of the modern-day technologies.

The study revealed that while some women entrepreneurs registered remarkable and difficult to ignore entrepreneurship success stories, some faced serious challenges that led to the total failure of their businesses. One of the major failures of women entrepreneurs in Zimbabwe is that the majority of them failed to motivate and satisfy their employees, to the extent that the majority of workers ended up leaving their organizations and absenting themselves from duty. The success of any organization, irrespective of size and complexity, depends on the motivation and job satisfaction levels of its employees (Nyanga et al 2018, Nyanga, 2018). One of the participants remarked, "Women entrepreneurs have a perception that workers look down upon them, hence, they are harsh and ill-treat their workers. Some workers are made to work for unpaid overtime or are not granted vacation days as prescribed in the Labour Act chapter 28;01. Such unfavourable work environments make workers emotionally, psychologically and mentally detached themselves from the activities of the organization, which consequently lead to poor performance." Participant 21 said, "I have been working for a female entrepreneur for 9 (nine) years, but I do not have a written formal employment contract. My employer therefore breaches the psychological contract as and when it best suits her. In order to retaliate, I do my private business within his business and also steal from her." Low job satisfaction results in workers engaging in unprofessional business activities and criminal acts, which have the potential to sink the organization. Bornali and Ajanta (2019) also argued that lack of finance, household poverty, low market rate, lack of education and lack of communication network are the main challenges encountered by rural women entrepreneurs. There are, however, some challenges which emerge as a result of employers' failure to address key human capital management fundamentals, such as giving workers living wages, satisfying workers and improving workers' working conditions.

Almost all the participants indicated that most women-owned and managed SMEs, have failed in recruiting, retaining and developing its human capital. Most women entrepreneurs hire semi-skilled and unskilled workers as a way of reducing their expenditure on wages and salaries. This view is in line with the Japanese saying that if you give your workers nuts you attract monkeys. Lowly paid workers find ways of feeding themselves from the activities of the organization without the authorization of the employer. Organizations should therefore employ skilled people who have the potential of giving an organization a competitive advantage. Women entrepreneurs compete with men entrepreneurs and other well-established organizations, hence, it is prudent that they hire people who are dedicated and loyal and have the stamina to give their organization a competitive edge. The results are in sync with 
those of Daelman (2019) who propounds that women entrepreneurship is not all about the money, but about doing the right things and taking the right decisions regarding employee resourcing. Most women entrepreneurs regard training and development of employees as a waste of resources, yet it is one of the key investment strategies. Furthermore, Sibande (2019) says that women entrepreneurs deprive themselves of acquiring skills, hence, they lack managerial skills needed to operate successful enterprises. Women entrepreneurs have also failed to reposition their customer value propositions, in order to remain competitive in the ever-changing environment which attracts big businesses. Apart from failing to properly manage the human resources, most women entrepreneurs failed to manage their financial resources in a business manner. Business finances are mixed with domestic finances, hence, domestic expenditure end up being taken care of by business finances. Failure to have financial discipline resulted in most women entrepreneurs using borrowed capital for domestic needs. Such financial indiscipline led to the closure of many SMEs managed by women in Zimbabwe.

To ensure that their businesses survive from various forms of micro and macro risks and threats, women entrepreneurs in Masvingo city, employed several survival strategies. Since 2000, the socio-economic environment in Zimbabwe has not been favourable for the survival and growth of start-ups, hence, for a start-up to survive, it needs to employ well-calculated strategies that give it an edge over its competitors. One of the strategies which are employed by women entrepreneurs is diversification. Women entrepreneurs create several business portfolios so as to spread the macro-environmental risks associated with their businesses. For instance, a woman entrepreneur in Masvingo started as a cross-border trader, buying and selling clothes from South Africa, but has since diversified and introduced a new strategic business unit that manufacture building materials such as window frames and door frames. The other survival strategy is in the pricing of goods and services, and in producing goods in bulk to benefit from the economies of scale. Most women entrepreneurs price and sell their goods and services in foreign currency and they sell at the going rate for the foreign currency exchange market. Furthermore, other women entrepreneurs do not trade using 'soft money' like EcoCash, bank transfers and swipe, but they rather demand all their clients to pay cash. Such a strategy was employed to hedge enterprises from the shortages of cash and foreign currency in the banking sector. For SMEs to restock, they require foreign currency, which is mostly available on the black market - an illegal and informal market - hence, they need cash to buy the foreign currency. Trading in cash also helps women entrepreneurs to avoid the $2 \%$ government charge on all payments made using other forms of payment such as EcoCash, swipe and money transfers. Though illegal, evading taxes such as the pay-as-you-earn tax, sales tax and other forms of production and operations taxes, is one of the strategies used by women entrepreneurs to make their businesses survive. The study also indicated that some women entrepreneurs hedge their money from inflation by opening and maintaining offshore accounts. The findings are consistent with Nyanga et al. (2013), who argued that for SMEs to survive during the economic meltdown, they had to employ several survival strategies, such as diversification and to source funding from financial institutions.

\section{Limitations}

The study faced the following limitations:

The researcher did not have adequate funding to finance the study and had to rely on financial assistance from friends and family members to finance the research. The financial resources, however, were inadequate to cover a wider geographical area and therefore the study had to be confined to Masvingo city. To reduce the impact of the problem, the researcher had to spend a longer period in the field, since he would only get to the respondents as and when he had acquired the necessary financial resources to cover stationery and other research-related costs. The other limitation of the study was that it was difficult to access women entrepreneurs, since they were always busy with their businesses, which caused failure from them to create time with the researcher. Not to disrupt their work schedules, some interviews were held after hours when the respondents had completed their day's work. The impact of the limitations of the study did not compromise the usefulness of the findings of the study to scholars, women entrepreneurs and policymakers.

\section{Conclusion}

The study came to the following conclusions: 1) A significant number of women entrepreneurs in Masvingo city in Zimbabwe reached remarkable milestones in terms of launching and growing their businesses. Some businesses started very well and they grew and managed to survive the threats and pressures of the macro-environmental factors. Some women-owned businesses have migrated from micro to macro enterprises. The ones that were successful, started small and grew to become the major players in their industries of operation. Women entrepreneurs are applauded for becoming risk-takers, and also for providing good leadership which led to the success of their enterprises. The major factors that propelled the growth and survival of women entrepreneurs was hard work, 
financial support from various stakeholders, and the utilization of contemporary communication systems such as social media. 2) The majority of women entrepreneurs who failed to grow their businesses, failed due to their failure to manage their human capital and financial resources. Women entrepreneurs struggle in setting up good work conditions that can help their organisations to attract and retain highly competent staff. There is very high labour turnover in SMEs, because of the poor working conditions and low wages and salaries and fewer opportunities for growth and promotion. Therefore, there is a need for key stakeholders to impart human resource management skills in women entrepreneurs, so that they can fully benefit from hiring and retaining competent staff. 3) Women entrepreneurs employ business diversification, pricing and quality service, and product strategies as their main strategies to keep their businesses afloat. There is a need to provide more funding to women entrepreneur enterprises to boost their financial base. Women entrepreneurs also need to continuously scan the macro- and micro-environments to benefit from all the opportunities that emerge, and also to deal with impending business threats.

\section{Reference}

Barbara, J. O., Catherine, E. \& Joanne, L. (2011). Feminist Attributes and Entrepreneurial Identity. Gender in Management. 26 (8): 561-589.

Black, E. L., Burton, F. G., Wood, D. A. \& Zimbelman, A. F. (2010). Entrepreneurial Success: Differing Perceptions of Entrepreneurs and Venture Capitalists. The International Journal of Entrepreneurship and Innovation. 11 (3), 189-198.

Bornali S. \& Ajanta B. R. (2019). A Study on The Problems Faced by Rural Women SHGS In Dibrugarh District, Assam. International Journal of Economics, Commerce and Research (IJECR), 9 (2), 29-38

Brush, C., Greene, P., Balachandra, L. \& Davis, A. (2018). The Gender Gap in Venture Capital Progress, Problems, and Perspectives. Venture Capital. 20 (2), 115-136. doi:10.1080/13691066.2017.1349266.

Carter, N., Brush, C., Greene, P., Gatewood, E. \& Hart, M. (2003). Women Entrepreneurs who Break through to Equity Financing: The Influence of Human, Social and Financial Capital. Venture Capital. 5 (1), 1-28. doi:10.1080/1369106032000082586

Coleman, S., \& Robb, A. (2009). A comparison of new firm financing by gender: evidence from the Kauffman Firm Survey data. Small Business Economics. 33 (4), 398-400.

Cuaton, G. (2019). A Post-Disaster study of a Women-led Handicraft Industry in Rural Philippines. Journal of Enterprising Communities: People and Places in the Global Economy, 13 (4), 489-507. https://doi.org/10.1108/JEC10-2018-0074

Daelman, I (2019). Women Entrepreneurship - It Is Not All About the Money. Proceedings of the Ninth International Conference on Engaged Management Scholarship https://ssrn.com/abstract=3454091 or http://dx.doi.org/10.2139/ ssrn. 3454091

Eddleston, K. A., Ladge, J.J., Mitteness, C. and Balachandra, L. (2016). Do You See What I See? Signaling Effects of Gender and Firm Characteristics on Financing Entrepreneurial Ventures". Entrepreneurship Theory and Practice. 40 (3), 489-514.

Erickson A.K. (2017). Women Entrepreneurship: Challenges and Way forward. Lilongwe. Almed Publishers.

Gayathridevi, C.L. (2014). Barriers of Women Entrepreneurs: A Study in Bangalore Urban District', International Journal of Trends in Economics Management and Technology (IJTEMT), 3 (2), 24-30.

Gukurume, S. \& Nyanga, T. (2012). Reconciling Work and School: A Case Study of Working Children in Mucheke Surburbs IN Masvingo. Journal of Sustainable Development in Africa, 20 (3).

Malmstrom, M. Johansson, J. and Wincent, J. (2017). Gender Stereotypes and Venture Support Decisions: How Governmental Venture Capitalists Socially Construct Entrepreneurs' Potential. Entrepreneurship Theory and Practice. 41 (5), 833-860.

Nyanga, T. (2018). Examining the Usefulness of Job Satisfaction Theories in Armed Conflict Society. Amity Global Human Resource Management Review, 8(2), 40-48.

Nyanga, T. \& Chindanya, A (2021) From Risk Aversion to Risk Loving: Strategies to Increase Participation of Female Entrepreneurs in Masvingo Urban, Zimbabwe. Ushus Journal of Business Management, 20 (1), 1-14. 
Nyanga, T. \& Tapfumanei, C.S. (2019). Collective Bargaining: A Catalyst for Dispute Resolution between Employers and Employees in the Retail Industry in Urban Mutare. Ushus Journal of Business Management (Christ University), 18 (1), 1-14.

Nyanga, T., Sibanda, R. \& Kruger J.W. (2018). Financial Growth and Stability in Armed Conflict Society: Does Job Satisfaction Play a Role? Amity Journal of Management Research, Vol.3 (1), $27-39$.

OECD (2015). Entrepreneurship at a Glance 2015. Entrepreneurship at a Glance. Paris: OECD Publishing. doi:10.1787/ entrepreneur_aag-2015-en

Scott, S. \& Venkatraman, S. (2000). The Promise of Entrepreneurship as a Field of Research. Academy of Management Review. 25: 217-226. doi:10.5465/amr.2000.2791611.

Sibande, M. V. (2019). The Perceptions of Township Entrepreneurs of Interventions Required to Reduce the High Failure Rate of Small, Medium and Micro Enterprises (SMMEs) in Ekurhuleni. https://hdl.handle.net/10539/28518

Yetisen, A. K, Volpatti L. R, Coskun, A. F., Cho S., Kamrani E, Butt H., Khademhosseini, A. \& Yun, S. H. (2015). Entrepreneurship Lab on a Chip. 15 (1), 3638-60. doi:10.1039/c5lc00577a

Tinkler, J. E., Bunker Whittington, K., Ku, M. C., \& Davies, A. R. (2015). Gender and Venture Capital DecisionMaking: The Effects of Technical Background and Social Capital on Entrepreneurial Evaluations. Social Science Research. 51: 1-16. doi:10.1016/j.ssresearch.2014.12.008

Zhang S.X.; Cueto, J. (2015). The Study of Bias in Entrepreneurship. Entrepreneurship Theory and Practice, 41 (3): 419-454. doi:10.1111/etap.12212. 